\title{
A Computational Approach to Incorporate Decelerating Log Phase in the Growth Kinetics of Indigenously Isolated Bacterial Strain Bacillus subtilis MN372379 During the Degradation of Congo Red Dye
}

\author{
Anuj Chaturvedi ${ }^{1}$, Birendra Rai ${ }^{1}$, Ram Singh ${ }^{1}$, and Ravi Jaiswal ${ }^{1}$ \\ ${ }^{1}$ Indian Institute of Technology BHU Varanasi
}

October 15, 2020

\begin{abstract}
Detailed knowledge of the bacterial growth kinetics is essential to ensure optimized biodegradation of the wastewater at high volume processing. A potential azo-dye degrading bacterium (Bacillus subtilis MN372379) was isolated from the sludge-waste nearby carpet-dyeing unit at Bhadohi in Uttar Pradesh, India. The isolated bacterial strain was used to decolorize simulated wastewater containing Congo Red dye in a batch reactor. This study primarily aimed at developing a parametric bacterial growth model to account the decelerating bacterial growth, caused by toxic metabolites present in the decelerating log phase, which was generally ignored in the previous studies. Specifically, this study proposed a computational approach to determine a time-averaged specific bacterial growth rate for the entire sigmoidal log phase, instead of using the conventional exponential growth kinetic which is valid only in the initial part of accelerating log phase. The nature of metabolite inhibition in the decelerating part of log phase was also determined and found to be non-competitive. Further, the computed time-averaged specific bacterial growth rate was incorporated into three substrate inhibition models to account for both, the metabolite- and substrate-, inhibitions, and their corresponding kinetic parameters were determined. Finally, the initial dye concentration and inoculum size were optimized to yield maximum dye utilization rate.
\end{abstract}

\section{Hosted file}

Manuscript.pdf available at https://authorea.com/users/367354/articles/486824-acomputational-approach-to-incorporate-decelerating-log-phase-in-the-growth-kineticsof-indigenously-isolated-bacterial-strain-bacillus-subtilis-mn372379-during-thedegradation-of-congo-red-dye

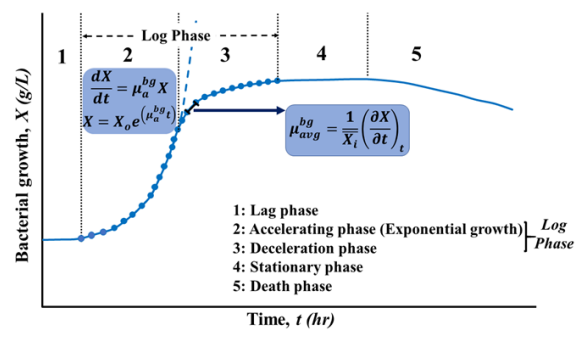

(a)

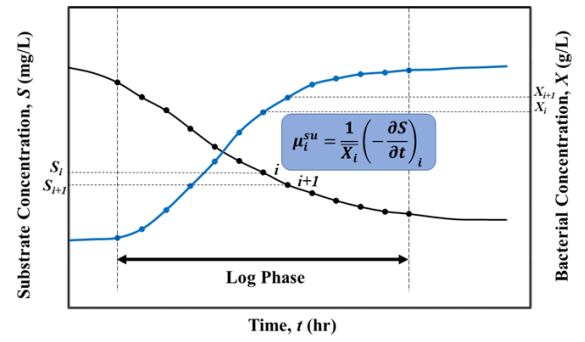

(b) 


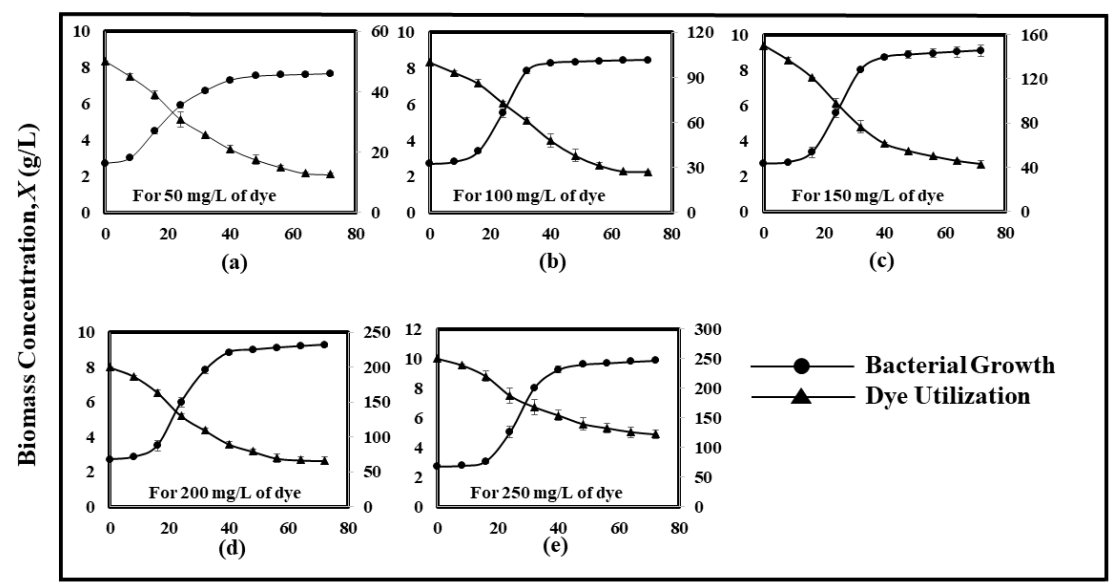

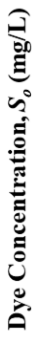

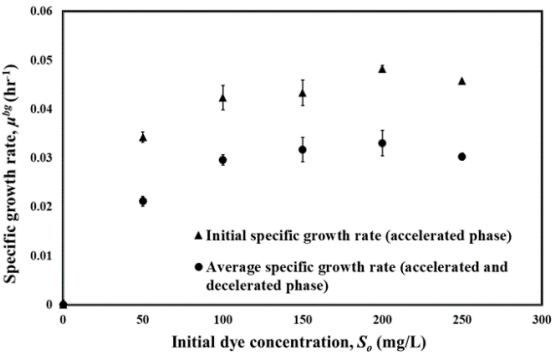

(a)

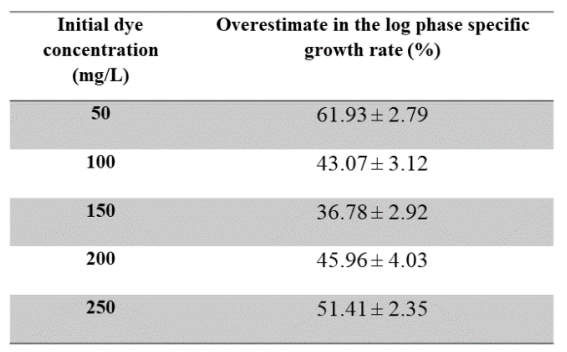

(b)

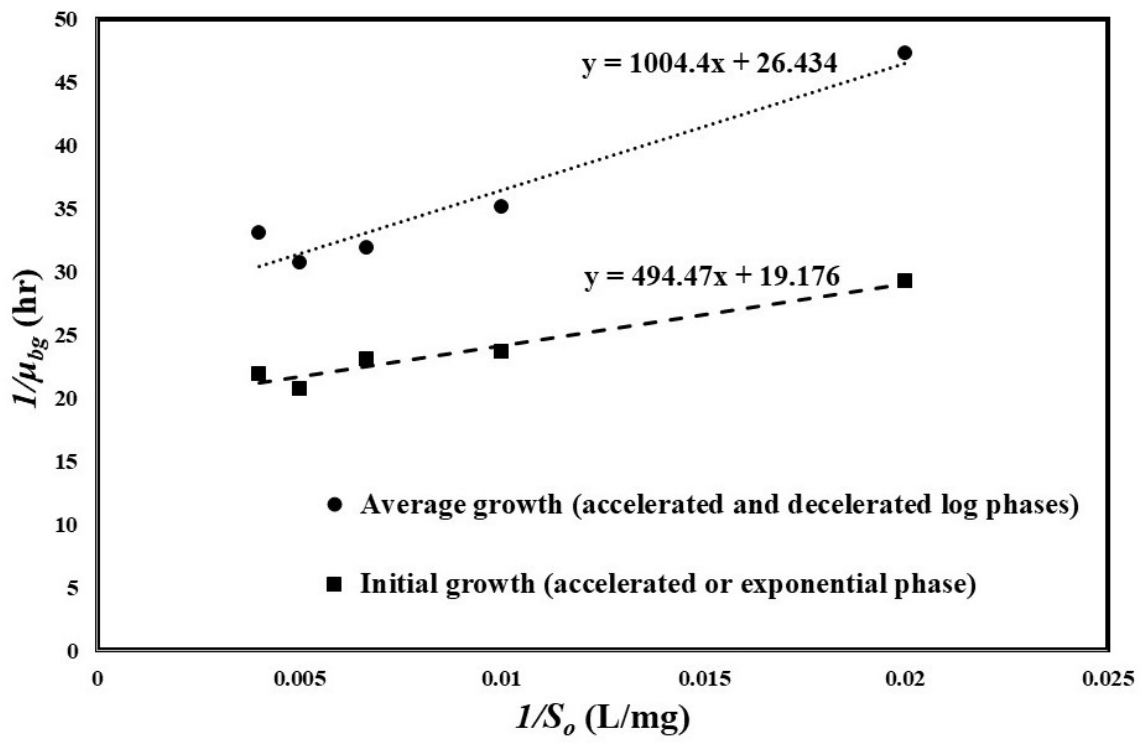



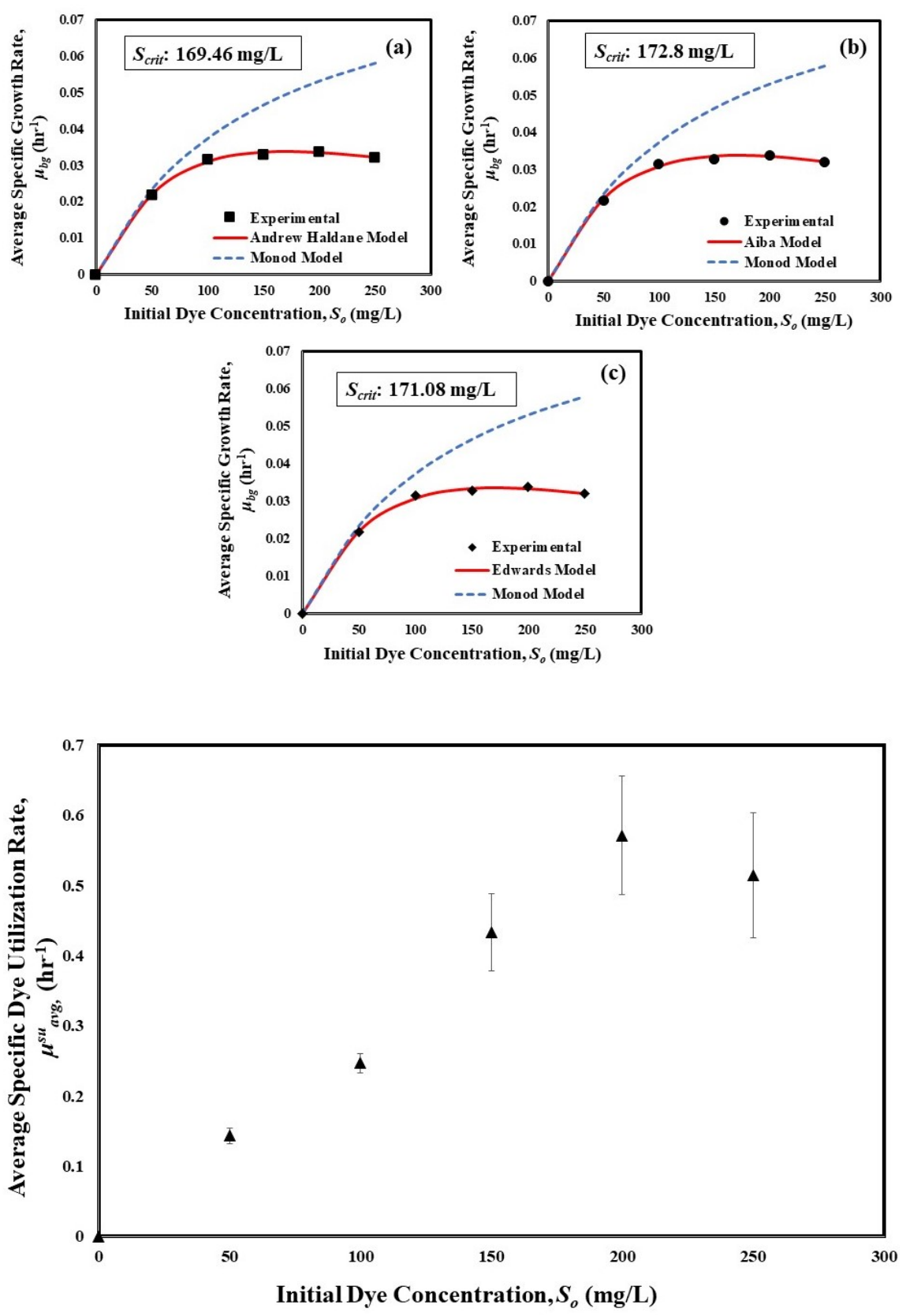

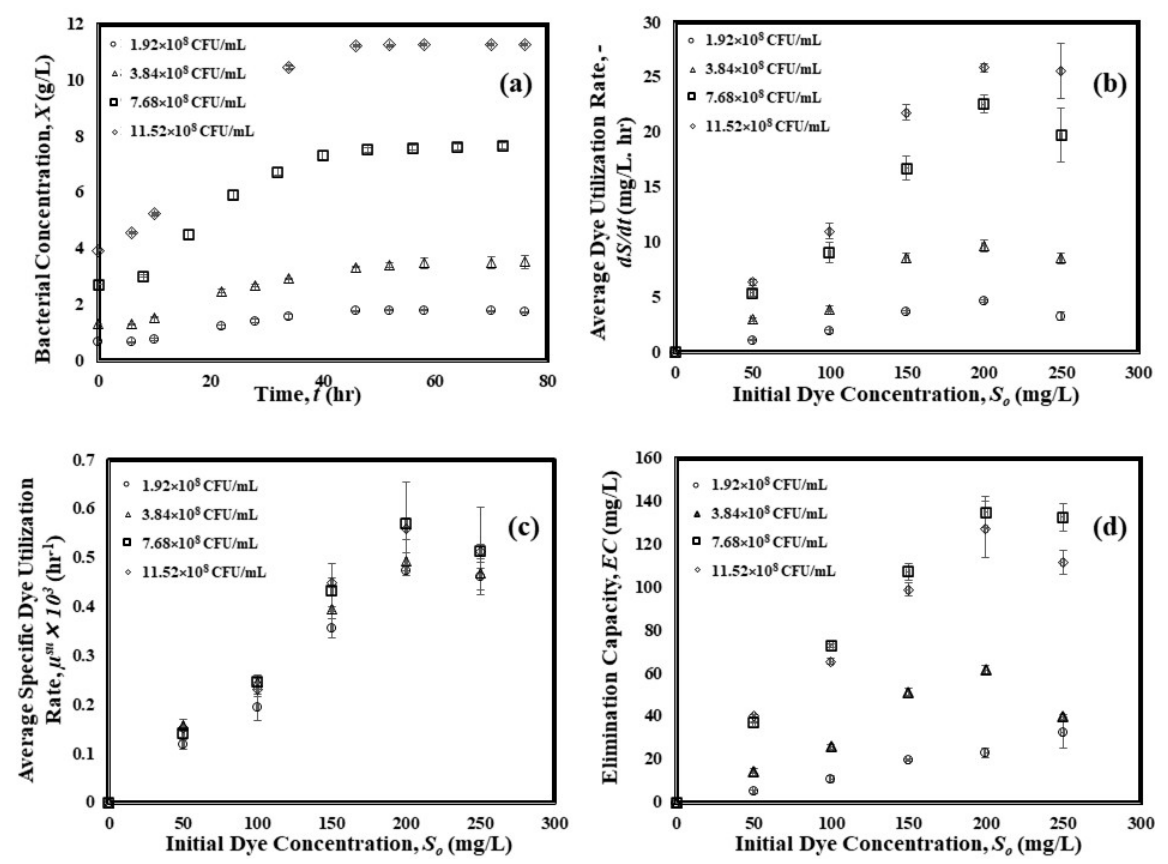